\title{
ANALISIS PERANCANGAN BASIS DATA SIPAM'S BERBASIS CHRONOLOGICAL FILLING SYSTEM
}

\author{
I Gede Susrama Mas Diyasa $^{1}$, Ni Made Ika Marini Mandeni ${ }^{2 *}$, Sugiarto ${ }^{3}$ \\ ${ }^{1,3}$ Informatika, Fakultas Ilmu Komputer, Universitas Pembangunan Nasional "Veteran” Jatim \\ ${ }^{1}$ igsusrama.if@upnjatim.ac.id \\ ${ }^{3}$ sugiarto.if@upnjatim.ac.id \\ ${ }^{2}$ Teknologi Informasi, Universitas Udayana, Jimbaran Bali \\ *Corresponding author email: made_ikamarini@unud.ac.id
}

\begin{abstract}
Abstrak - Pengelolaan surat-menyurat di instansi pemerintah dan swasta saat ini tidak bisa dipisahkan dengan perkembangan teknologi informasi, yang dulunya surat-menyurat dilakukan secara konvensional berubah ke modernisasi administrasi seperti sistem untuk melakukan pengarsipan surat. Proses peng-agendaan surat masuk dan surat keluar masih dilakukan dengan cara memisahkan antara surat masuk dan surat keluar. Disebabkan oleh jumlah data yang sangat banyak jika data tidak dikelola dengan baik, teratur dan teliti, maka akan menimbulkan suatu permasalahan, Sistem Informasi Pengelolaan Administrasi Dan Manajemen Pengarsipan Surat (SIPAM'S) Berbasis Chronological Filling System merupakan sebuah sistem informasi yang digunakan untuk pengarsipan surat, maka dari itu sebelum melakukan perancangan sistem informasi tersebut perlu adanya analisis perancangan basis data. Dalam melakukan analisis dan perancangan basis data untuk SIPAM'S, proses yang dilakukan dimulai dengan studi literatur, observasi untuk pengumpulan data, desain sistem basis data dan hasil basis data. Hasil basis data yang diperoleh dari proses tersebut dapat digunakan untuk menyimpan data yang berkaitan dengan data pengarsipan surat dalam sebuah instansi. Dengan hasil analisis dan perancangan basis data SIPAM'S akan mempermudah dalam hal pembuatan sistem informasi, mempermudah pencatatan data dan mempermudah dalam melakukan manajemen data arsip surat.
\end{abstract}

Kata Kunci- analisis, basis data, sipam's, Chronological Filling System.

\section{Pendahuluan}

Suatu instansi pemerintah dan swasta akan selalu mengikuti perkembangan teknologi informasi, termasuk dalam melalukan modernisasi administrasi seperti sistem untuk melakukan pengarsipan surat. Karena masih ada beberapa instansi yang menggunakan cara manual seperti menggunakan buku besar sebagai pencatatan ataupun menggunakan komputer dengan manual untuk mencatat surat masuk dan keluar sebagai arsip [1].

Arsip merupakan rekaman suatu kegiatan maupun berupa suatu peristiwa yang terdiri dari berbagai bentuk data atau media sesuai dengan perkembangan teknologi informasi yang dibuat dan diterima oleh perseorangan, organisasi kemasyarakatan, organisasi politik, lembaga pendidikan, perusahaan maupun lembaga Negara (pemerintahan daerah dan pusat) dalam pelaksanaan kehidupan bermasyarakat, berbangsa, dan bernegara (PP 28 Tahun 2012) [2].
Proses pengagendaan surat masuk dan surat keluar masih dilakukan dengan cara memisahkan antara surat masuk dan surat keluar. Disebabkan oleh jumlah data yang sangat banyak jika data tidak dikelola dengan baik, teratur dan teliti, maka akan menimbulkan suatu permasalahan, sehingga diperlukan pembuatan sistem informasi administrasi dan manajemen pengarsipan surat yang mendukung kinerja dari instansi atau perusahaan yang bersangkutan [3]. Untuk mendukung sistem informasi pengarsipan surat yang mudah digunakan maka diperlukan struktur basis data yang baik sehingga dapat mempermudah programmer back-end [4] untuk menyelesaikan tugasnya [5].

Beberapa penelitian yang terkait dengan sistem informasi Tata Kelola Administrasi Dan Manajemen Pengarsipan Surat, salahsatunya adalah penelitain pada referensi [6], yaitu mengembangkan dan menggunakan Electronic File Tracking System (EFTS) untuk meningkatkan produktivitas di antara personil administrasi [6]. EFTS yang dikembangkan dalam makalah ini adalah aplikasi web yang mampu mengelola pembuatan, dan perpindahan file dari meja ke meja staf yang mengerjakannya. Sistem ini dikembangkan dengan perangkat lunak sumber terbuka setelah menetapkan persyaratan fungsional dan non-fungsional yang vital dan alur kerja yang terperinci.

Pada referensi [7], yaitu menganalisis sistem informasi disposisi surat keluar dan surat masuk berbasis android dengan menggunakan metode Livensten Distance, namun pada penelitian ini hanya menekankan pada proses pencarian surat dan aplikasi hanya bisa digunakan jika sudah tahu username dan password. Selain itu referensi [8] memfokuskan perancangan aplikasi Pengarsipan Dan Disposisi Surat dengan menggunakan proses perancangan model waterfall dan Graphql.

Peneliti lainnya pada referensi [9], membahas sistem Informasi Manajemen Surat berbasis PHP dan Mysq, pada sistem yang dibuat hanya ada proses disposisi surat tanpa ada proses pencarian dan proses penyimpanan data surat berdasarkan suatu metode tertentu.

Dengan demikian, pada penelitian ini didesain dan menerapkan sebuah struktur basis data ke sistem informasi pengarsipan surat guna menunjang pengagendaan surat masuk dan surat keluar dengan metode Chronological Filling System [10] akan menjadikan pengarsipan lebih cepat, mudah dan efisien terhadap penggunaan kertas pada sebuah instansi. 
Agar pembahasan dapat dilakukan sesuai kebutuhan pengguna, maka pada penelitian ini dibatasi masalah yang akan dibahas yaitu sistem hanya menangani pengarsipan untuk dokumen surat-menyurat dan file-file penting lainnya yang berbentuk file pdf dalam satu surat hanya satu file. Basis data dari hasil perancangan sistem ini disarankan agar diterapkan pada server web, Sistem ini menggunakan metode Chronological Filing System dalam sistem penyimpanan kearsipan.

\section{Metode}

Metodologi penelitian pada perancangan basis data SIPAM's dijelaskan pada Gambar 1

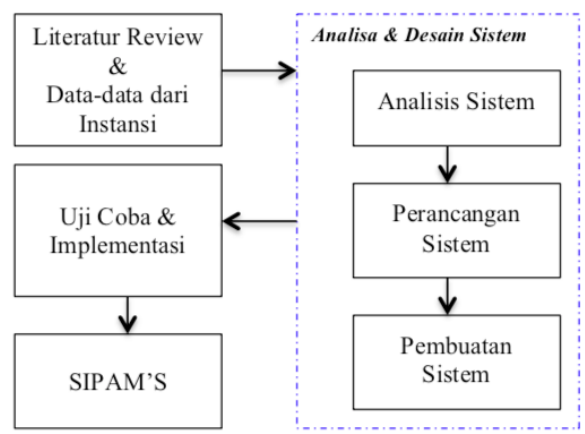

Gbr. 1 Metodologi Analisis dan Perancangan Basis Data SIPAM's.

\section{A. Literatur review dan data}

Literatur review [11] dilakukan untuk mempelajari hal-hal yang terkait dengan analisa perancangan basis data dan juga menggali beberapa informasi mengenai SIPAM's.

Cara yang digunakan untuk pengumpulan data untuk melengkapi penelitian ini yaitu : 1). Observasi [12] ke administrasi instansi, dalam penelitian ini dilakukan di beberapa instansi pemerintah daerah, 2). Melakukan interview dengan administrasi dan pimpinan instansi perusahaan, 3). Melakukan pengulasan dari buku pegangan instansi, jurnal dan buku pendukung

\section{B. Desain Sistem}

Proses yang ada pada tahap desain sistem meliputi analisis Sistem, perancangan Sistem dan perancangan CDM dan PDM [13]

\section{Analisis Sistem}

Analisa yang dilakukan pada penelitian ini dimulai dari analisa proses bisnis yang berjalan secara umum pada sebuah instansi. Proses bisnis adalah suatu kumpulan aktivitas atau pekerjaan terstruktur yang saling terkait untuk menyelesaikan suatu masalah tertentu atau yang menghasilkan produk atau layanan (demi meraih tujuan tertentu).

1. Proses Sistem yang berjalan, ini diperoleh secara umum dari beberapa instansi Pemerintah Daerah yang masih menggunakan cara manual dalam melakukan pencatatan, pendisposisian surat masuk dan pembuatan surat keluar. Dalam penulisan diagram alir [14] ini jabatan yang ditulis adalah sebagai contoh, dimana kepala dinas adalah level tertinggi di instansi, kepala bagian adalah level tengah dan staff adalah level terendah. Sistem yang akan dirancang menetapkan user secara dinamis.

2. Analisa Kekurangan [15]. Berdasarkan penjelasan tentang analisis sistem yang berjalan, maka dapat disimpulkan beberapa kelemahan yaitu :

a) Proses perpindahan data surat masuk dari admin ke Kepala dinas dan seterusnya memerlukan waktu yang lumayan.

b) Bahaya kehilangan data arsip yang disebabkan oleh kerusakan buku arsip masuk ataupun pc yang digunakan.

c) Proses pencarian data surat yang membutuhkan waktu lama.

d) Banyaknya kertas yang digunakan untuk pengarsipan.

e) Jika Kepala dinas menginginkan laporan arsip maka sistem yang berjalan akan memakan waktu yang lama dalam pembuatan laporan.

f) Proses persetujuan surat keluar yang membutuhkan waktu lama

3. Analisa Sistem [16]. SIPAM's ini mencakup dalam hal input surat masuk maupun surat keluar oleh admin dan mempermudah dalam hal pendisposisian surat oleh Kepala Dinas dan Kepala Bagian. Surat yang berjalan akan berupa data digital, sehingga tidak ada lagi surat fisik yang akan didisposisikan kepada tujuan. Dalam hal pembuatan surat keluar sistem ini terdapat fungsi penyetujuan surat oleh Kepala Bagian ataupun Kepala Dinas. Hasil yang diharapkan dari perancangan basis data ini adalah sebuah basis data yang akan diterapkan pada server yang menggunakan API untuk komunikasi terhadap pengguna. Alur sistem yang akan dibuat akan digambarkan seperti pada Gambar 2.

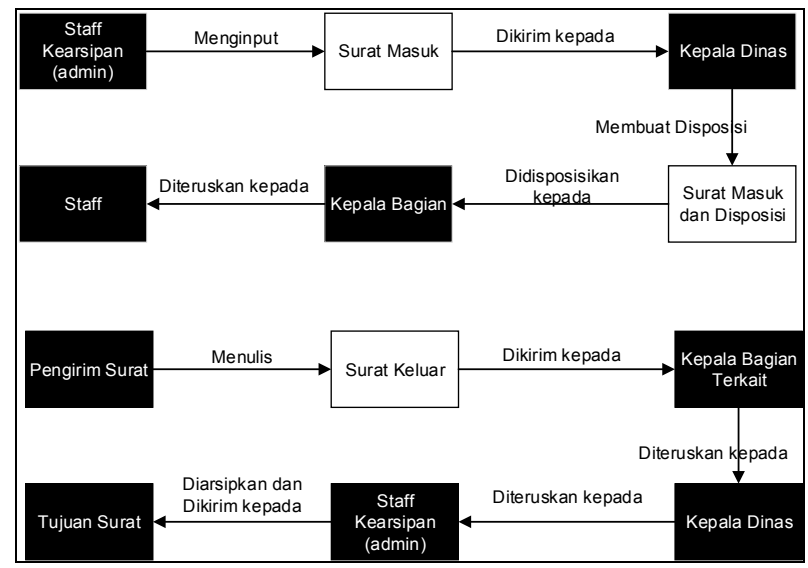

Gbr. 2 SIPAM's.

4. Analisa kebutuhan sistem [17]. Dari hasil analisa SIPAM's, ditemukan beberapa kebutuhan yang digunakan untuk membangun sistem yaitu:

a. Data Arsip terdiri dari: id, kode arsip, nama, tempat, keterangan, tanggal.

b. Data Surat Masuk terdiri dari: id, nomor surat, asal, lampiran, perihal, file, sifat, tanggal. 
c. Data Surat Keluar terdiri dari: id, nomor surat, perihal, lampiran, perihal, lampiran, tujuan, isi, tembusan, kota, file lampiran, tanggal.

d. Data User terdiri dari: id, nip, nama, password, tanggal, token.

e. Data Bagian: id, nama, tanggal.

f. Data Level: id, level, tanggal.

g. Data Sifat surat terdiri dari: id, nama, tanggal.

h. Sistem akan dibangun dengan user dinamis sehingga admin lebih mudah untuk mengatur struktur sesuai yang dimiliki oleh instansi

i. Proses pada SIPAM's yaitu pengelolaan arsip dan surat, mengarsipkan surat masuk dan keluar, monitoring disposisi dan persetujuan surat.

j. Informasi yang dihasilkan berupa surat masuk dan keluar, arsip, status disposisi, status persetujuan, dan laporan kearsipan dan surat.

k. Terdapat data bagian, level dan user digunaka untuk memanajemen user secara dinamis.

\section{Perancangan Sistem}

Dalam perancangan sistem, akan digunakan beberapa permodelan yaitu Conceptual Data Model, Physical Data Model dan Logical Data Model.

a) Conceptual Data Model (CDM) [18], pada perancangan basis data SIPAM,s model CDM ini ditunjukan tabel yang berisi atribut yang merupakan bagian dari entitas. Setiap entitas memiliki satu kata kunci (primary key) yang bersifat unik dan setiap entitas akan berhubungan dengan entitas lain (relationships), CDM SIPAM's dapat dilihat pada Gambar 3.

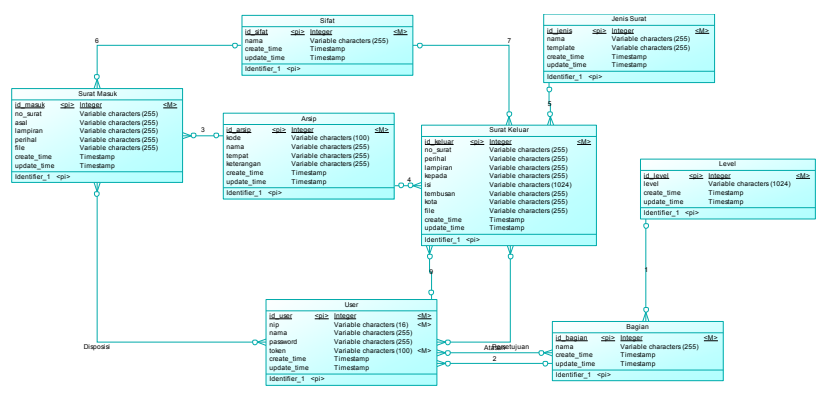

Gbr. 3 CDM SIPAM's

b) Physical Data Model (PDM) [19], merupakan model SIPAM's yang merepresentasikan dalam bentuk tabel yang terstruktur, yang terdiri dari foreign key, primary key, kolom, tipe data kolom serta relationships yang menghubungkan satu tabel dengan tabel lainnya.

c) Logical Data Model (LDM) [20], merupakan suatu proses membangun sebuah model, dalam hal ini adalah SIPAM's dari informasi yang digunakan oleh instansi pemerintah daerah berdasarkan sebuah model data spesifik. Tujuan membangun LDM ini yaitu membangun suatu data model logikal lokal dari data model konseptual dengan menggambarkan pandangan khusus dari instansi, kemudian untuk memvalidasi model LDM ini, untuk memastikan bahwa model LDM tersebut benar dan untuk memastikan bahwa model tersebut mendukung transaksi SIPAM's yang diperlukan, LDM SIPAM's dapat dilihat pada Gambar 4.

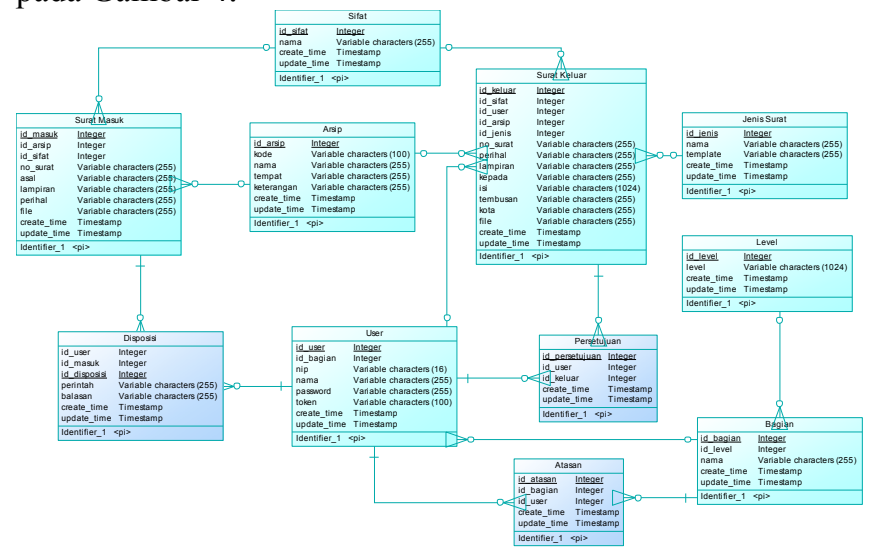

Gbr. 4 LDM SIPAM's.

\section{HASIL DAN PEMBAHASAN}

Penelitian ini menghasilkan sebuah rancangan basis data dan sistem yang akan dibangun berdasarkan kebutuhan sistem dan perancangan sistem basis data yang sudah didapatkan.

\section{A. Hasil Basis Data}

Setelah melakukan perancangan sistem pada bab metodologi, telah ditemukan beberapa tabel yang akan digunakan dalam SIPAM's ini. Tabel lansung diterapkan kedalam beberapa model diatas. Tabel yang diperoleh meliputi 8 tabel dari entitas dan 3 tabel relasi. Keterangan setiap tabel dapat dilihat dari Tabel I sampai Tabel XI, Tabel I, adalah tabel User yang digunakan untuk menyimpan data user dan untuk data login

TABEL I

TABEL USER

\begin{tabular}{|l|l|l|l|}
\hline $\begin{array}{l}\text { Nama } \\
\text { Field }\end{array}$ & Type & Keterangan & Contoh \\
\hline id_user & int & Primary Key tabel user & 1 \\
\hline id_bagian & int & $\begin{array}{l}\text { Foreign Key dari tabel } \\
\text { bagian, berguna untuk } \\
\text { memberi keterangan } \\
\text { bagian bagi user }\end{array}$ & 2 \\
\hline nip & varchar(16) & $\begin{array}{l}\text { Nomor induk user, } \\
\text { bukan sebagai PK }\end{array}$ & 198503302 \\
\hline nama & varchar(255) & nama asli user & rico sandyca \\
\hline password & varchar(255) & $\begin{array}{l}\text { keamanan untuk login, } \\
\text { dengan enkripsi }\end{array}$ & $\begin{array}{l}\$ 2 \mathrm{y} \$ 10 \$ \mathrm{~b} 0 \mathrm{eR} 6 \\
\ldots \ldots\end{array}$ \\
\hline $\begin{array}{l}\text { token } \\
\text { narchar(100) }\end{array}$ & $\begin{array}{l}\text { sebagai string } \\
\text { keamanan untuk akses } \\
\text { sistem }\end{array}$ & $\begin{array}{l}482 \mathrm{fa} 09 \mathrm{~b} 1 \mathrm{df} 229 \\
1 \ldots .\end{array}$ \\
\hline $\begin{array}{l}\text { update_ti } \\
\text { me }\end{array}$ & timestamp & waktu create data & $\begin{array}{l}07 / 05 / 2019 \\
13: 59\end{array}$ \\
\hline
\end{tabular}

Tabel 2, adalah tabel Level digunakan untuk membantu leveling struktur organisasi. 
TABEL II

TABEL LEVEL

\begin{tabular}{|l|l|l|l|}
\hline Nama Field & Type & Keterangan & Contoh \\
\hline id_level & int & $\begin{array}{l}\text { Primary key } \\
\text { tabel level }\end{array}$ & 1 \\
\hline level & varchar(1024) & Level ke- & Kepala Bagian TU \\
\hline create time & timestamp & $\begin{array}{l}\text { waktu create } \\
\text { data }\end{array}$ & $07 / 05 / 201913: 59$ \\
\hline update_time & timestamp & $\begin{array}{l}\text { waktu update } \\
\text { data }\end{array}$ & $07 / 05 / 201913: 59$ \\
\hline
\end{tabular}

Tabel 3 adalah Tabel Bagian, yang digunakan untuk menyimpan data bagian structural organisasi

TABEL III

TABEL BAGIAN

\begin{tabular}{|l|l|l|l|}
\hline Nama Field & Type & Keterangan & Contoh \\
\hline id_bagian & int & $\begin{array}{l}\text { Primary key tabel } \\
\text { bagian }\end{array}$ & 1 \\
\hline & & $\begin{array}{l}\text { Foreign key dari } \\
\text { tabel level, untuk } \\
\text { mengetahui level } \\
\text { struktural bagian }\end{array}$ & 1 \\
\hline id_level & int & nama bagian & $\begin{array}{l}\text { Kepala Bagian } \\
\text { TU }\end{array}$ \\
\hline nama & varchar(255) & waktu create data & $\begin{array}{l}07 / 05 / 2019 \\
13: 59\end{array}$ \\
\hline create time & timestamp & waktu update data & $\begin{array}{l}07 / 05 / 2019 \\
13: 59\end{array}$ \\
\hline update time & timestamp & & \\
\hline
\end{tabular}

Tabel 4. Adalah Tabel Arsip yang digunakan untuk menyimpan data arsip

TABEL IV

TABEL ARSIP

\begin{tabular}{|l|l|l|l|}
\hline Nama Field & Type & Keterangan & Contoh \\
\hline id_arsip & int & $\begin{array}{l}\text { Primary Key tabel } \\
\text { arsip }\end{array}$ & 1 \\
\hline kode & varchar(100) & $\begin{array}{l}\text { Sebagai kode } \\
\text { arsip sesuai } \\
\text { dengan aslinnya }\end{array}$ & ARS-01 \\
\hline nama & varchar(255) & Nama Arsip & Arsip Keuangan \\
\hline tempat & varchar(255) & $\begin{array}{l}\text { Letak } \\
\text { penyimpanan } \\
\text { arsip }\end{array}$ & Ruang 01 \\
\hline keterangan & varchar(255) & $\begin{array}{l}\text { keterangan } \\
\text { keguanaan arsip }\end{array}$ & Arsip Keuangan \\
\hline create_time & timestamp & waktu create data & $\begin{array}{l}07 / 05 / 2019 \\
13: 59\end{array}$ \\
\hline update_time & timestamp & waktu update data & $\begin{array}{l}07 / 05 / 2019 \\
13: 59\end{array}$ \\
\hline
\end{tabular}

Tabel 5 adalah Tabel Sifat untuk klasifikasi sifat surat

TABEL V

TABEL SIFAT

\begin{tabular}{|l|l|l|l|}
\hline Nama Field & Type & Keterangan & Contoh \\
\hline id_sifat & int & $\begin{array}{l}\text { Primary key tabel } \\
\text { sifat }\end{array}$ & 1 \\
\hline sifat & varchar(255) & nama sifat surat & Penting \\
\hline create time & timestamp & waktu create data & $07 / 05 / 201913: 59$ \\
\hline update_time & timestamp & waktu update data & $\begin{array}{l}07 / 05 / 2019 \\
13: 59\end{array}$ \\
\hline
\end{tabular}

TABEL VI

TABEL JENIS SURAT

\begin{tabular}{|l|l|l|l|}
\hline $\begin{array}{l}\text { Nama } \\
\text { Field }\end{array}$ & Type & Keterangan & Contoh \\
\hline id_jenis & int & $\begin{array}{l}\text { Primary key tabel } \\
\text { jenis }\end{array}$ & 1 \\
\hline nama & varchar(255) & nama jenis surat & Surat Himbauan \\
\hline untuk & $\begin{array}{l}\text { Surat } \\
\text { pengambilan file } \\
\text { saat cetak }\end{array}$ & Himbauan.html \\
\hline $\begin{array}{l}\text { waktu create data } \\
\text { create_time }\end{array}$ & timestamp & varchar(255) \\
\hline \begin{tabular}{l} 
update \\
\hline
\end{tabular} & timestamp & waktu update data & $07 / 05 / 20191313: 59$ \\
\hline
\end{tabular}

Tabel VI adalah Tabel Jenis surat yang digunakan untuk menyimpan jenis surat keluar, dan Tabel VII adalah Tabel Surat Masuk yang digunakan untuk menyimpan data surat masuk.

TABEL VII

TABEL SURAT MASUK

\begin{tabular}{|l|l|l|l|}
\hline $\begin{array}{l}\text { Nama } \\
\text { Field }\end{array}$ & Type & Keterangan & Contoh \\
\hline id_masuk & int & $\begin{array}{l}\text { Primary key tabel } \\
\text { surat masuk }\end{array}$ & 1 \\
\hline id arsip & int & $\begin{array}{l}\text { Foreign key dari } \\
\text { tabel arsip }\end{array}$ & 1 \\
\hline id_sifat & int & $\begin{array}{l}\text { Foreign key dari } \\
\text { tabel sifat }\end{array}$ & 1 \\
\hline no_surat & varchar(255) & $\begin{array}{l}\text { nomer surat dari } \\
\text { surat fisik }\end{array}$ & $\begin{array}{l}\text { SMK- } \\
\text { AI/VIII/2017 }\end{array}$ \\
\hline asal & varchar(255) & $\begin{array}{l}\text { asal pengiriman } \\
\text { surat }\end{array}$ & PT. Nusantara 2 \\
\hline lampiran & varchar(255) & $\begin{array}{l}\text { lampiran yang ada } \\
\text { dalam surat fisik }\end{array}$ & 1 lembar \\
\hline perihal & varchar(255) & $\begin{array}{l}\text { perihal yang ada } \\
\text { dalam surat fisik }\end{array}$ & $\begin{array}{l}\text { Peminjaman } \\
\text { Fasilitas }\end{array}$ \\
\hline file & varchar(255) & $\begin{array}{l}\text { Direktori file pdf } \\
\text { surat masuk }\end{array}$ & surat/sm_1.pdf \\
\hline create time & timestamp & waktu create data & 07/05/2019 13:59 \\
\hline update time & timestamp & waktu update data & $07 / 05 / 201913: 59$ \\
\hline
\end{tabular}

Tabel VIII adalah tabel relasi disposisi, yaitu digunakan untuk menyimpan data disposisi surat masuk, dan Tabel IX adalah table Surat Keluar, yang digunakan untuk menyimpan data surat keluar

TABEL VIII

TABEL RELASI Disposis

\begin{tabular}{|l|l|l|l|}
\hline $\begin{array}{l}\text { Nama } \\
\text { Field }\end{array}$ & Type & Keterangan & Contoh \\
\hline id_disposisi & int & $\begin{array}{l}\text { Primary key tabel } \\
\text { disposisi }\end{array}$ & 1 \\
\hline id_user & int & $\begin{array}{l}\text { Foreign key dari } \\
\text { tabel user } \\
\text { (penerima } \\
\text { disposisi) }\end{array}$ & 2 \\
\hline id_masuk & int & $\begin{array}{l}\text { Foreign key dari } \\
\text { tabel surat masuk }\end{array}$ & 2 \\
\hline perintah & varchar(255) & Perintah disposisi & $\begin{array}{l}\text { Teruskan ke } \\
\text { bawahan }\end{array}$ \\
\hline balasan & varchar(255) & $\begin{array}{l}\text { tanggapan } \\
\text { penerima disposisi }\end{array}$ & Laksanakan \\
\hline create_time & timestamp & waktu create data & $07 / 05 / 201913: 59$ \\
\hline update_time & timestamp & waktu update data & 07/05/2019 13:59 \\
\hline
\end{tabular}


TABEL IX

TABEL SURAT KELUAR

\begin{tabular}{|l|l|l|l|}
\hline Nama Field & Type & Keterangan & Contoh \\
\hline id_keluar & int & $\begin{array}{l}\text { Primary key } \\
\text { tabel surat } \\
\text { keluar }\end{array}$ & 1 \\
\hline id_user & int & $\begin{array}{l}\text { Foreign key dari } \\
\text { tabel user untuk } \\
\text { pembuat surat }\end{array}$ & 5 \\
\hline id_arsip & int & $\begin{array}{l}\text { Foreign key dari } \\
\text { tabel arsip }\end{array}$ & 1 \\
\hline id_sifat & int & $\begin{array}{l}\text { Foreign key dari } \\
\text { tabel sifat }\end{array}$ & 1 \\
\hline id jenis & int & $\begin{array}{l}\text { Foreign key dari } \\
\text { tabel jenis }\end{array}$ & 2 \\
\hline no_surat & varchar(255) & $\begin{array}{l}\text { nomer surat } \\
\text { yang akan } \\
\text { dibuat }\end{array}$ & $1 /$ SBY/VIII/2017 \\
\hline kepada & varchar(255) & $\begin{array}{l}\text { tujuan } \\
\text { pengiriman } \\
\text { surat }\end{array}$ & PT. 03persatuan \\
\hline lampiran & varchar(255) & $\begin{array}{l}\text { lampiran surat } \\
\text { yang dibuat }\end{array}$ & 1 lembar \\
\hline perihal & varchar(255) & $\begin{array}{l}\text { perihal yang } \\
\text { akan dibuat }\end{array}$ & Peminjaman \\
\hline Fasilitas
\end{tabular}

Tabel IX adalah tabel relasi Persetujuan untuk menyimpan data persetujuan surat keluar, dan Tabel $\mathrm{X}$ adalah tabel relasi Atasan, yang digunakan untuk menyimpan data user atasan dari data bagian.

TABEL X

Tabel Relasi Persetujuan Surat Keluar

\begin{tabular}{|l|l|l|l|}
\hline Nama Field & Type & Keterangan & Contoh \\
\hline id_persetujuan & int & $\begin{array}{l}\text { Primary key } \\
\text { tabel disposisi }\end{array}$ & 1 \\
\hline id_user & int & $\begin{array}{l}\text { Foreign key dari } \\
\text { tabel user (yang } \\
\text { harus } \\
\text { menyetujui) }\end{array}$ & 2 \\
\hline & & $\begin{array}{l}\text { Foreign key dari } \\
\text { tabel surat } \\
\text { keluar, surat } \\
\text { yang harus } \\
\text { disetujui }\end{array}$ & 1 \\
id_keluar & int & $\begin{array}{l}\text { waktu create } \\
\text { data }\end{array}$ & $07 / 05 / 201913: 59$ \\
\hline create_time & timestamp & $\begin{array}{l}\text { waktu update } \\
\text { data }\end{array}$ & $07 / 05 / 201913: 59$ \\
\hline update_time & timestamp &
\end{tabular}

\section{B. Pembahasan}

Dari semua tabel yang ada dalam hasil basis data, masingmasing tabel memiliki id sebagai Primary Key (PK) untuk alasan keamanan data dalam sistem. Pada awalnya sistem ini akan dibangun dengan pemanfaatan API yang dapat diakses mudah oleh user, sehingga ketika terdapat perubahan atau dalam penginputan data tidak terdapat masalah yang fatal karena terdapat PK yang sama.

\section{KESIMPULAN}

Hasil dari analisa basis data Sistem Informasi Pengelolaan Administrasi Dan Manajemen Pengarsipan Surat (SIPAM'S) Berbasis Chronological Filling System ini mengahasilkan sebuah tempat penyimpanan untuk data-data penting yang digunakan pada sistem informasi tata kelola administrasi dan manajemen pengarsipan surat berbasis chronological filling system, dapat memudahkan admin untuk mengelola data yang sebelumnya masih manual dan kurang efektif menjadi lebih efektif, terkomputerisasi dan lebih terstruktur.

\section{UCAPAN TERIMA KASIH}

Terima kasih disampaikan kepada Tim SANTIKA atas yang telah memberikan wadah bagi kami semua untuk terus mengembangkan ilmu pengetahuan sehingga dapat memberikan banyak kontribusi bagi secara akademis maupun dampak positif dimasyarakat

\section{REFERENSI}

[1] Ramadani, R. (2019). Pengelolaan arsip dinamis (surat masuk dan surat keluar) di Universitas Indo Global Mandiri. IORA: Jurnal Ilmu Perpustakaan Dan Informasi (e-Journal), 12(2), 118. https://doi.org/10.30829/iqra.v12i2.3987

[2] Pamungkas, J., \& Suliyati, T. (2017). Implementasi Pp 28 Tahun 2012 Dalam Pengelolaan Arsip Narkotika Di Badan Narkotika Nasional (Bnn) Pusat Jakarta. Jurnal Ilmu Perpustakaan, 6(3), 91-100. https://ejournal3.undip.ac.id/index.php/jip/article/view/23136

[3] Diana, I. N., Anwar, M. M., N, R. S., \& D, I. G. S. M. (2019). Analisis Perancangan Sistem Informasi Pengarsipan Dan Disposisi Surat Berbasis Chronological Filling System. September, 27-32. http://santika.ijconsist.org/index.php/SANTIKA/article/view/11/10

[4] Hatala, Z. (2019). Prosedur efektif pengembangan aplikasi basis data JSAI (Journal Scientific and Applied Informatics), 2(1). https://doi.org/10.36085/jsai.v2i1.104

[5] Budiwitjaksono, G. S., Ade, I., Sampurno, W., Made, N., \& Marini, I. (2020). Graph-QL Responsibility Analysis at Integrated Competency Certification Test System Base on Web. 11(2), 114-123.

[6] Eder, M. S.-. (2015). E-Document Tracking System. III(3), 2731-2747.

[7] Diana, I. N., Susrama, I. G., \& Diyasa, M. (2020). Analisis Perancangan Aplikasi Pengarsipan Dan. 1(2), 584-593.

[8] Rico Sandyca Novenza, I Gede Susrama Mas Diyasa, Sugiarto (2020) Sistem Informasi Disposisi Surat Berbasis Api Menggunakan Graphq1, Jurnal Informatika dan Sistem Informasi (JIFoSI) Vol. 1, No. 2, hal. 467-477

[9] Diana, I. N., Susrama, I. G., \& Diyasa, M. (2020). Analisis Perancangan Aplikasi Pengarsipan Dan. 1(2), 584-593.

[10] Yusti, I. (2016). Sistem Informasi Manajemen Surat Berbasis Php Dan Mysql Di Institut Seni Indonesia Padangpanjang. Jurnal Sains Dan Teknologi: Jurnal Keilmuan Dan Aplikasi Teknologi Industri, 16(1), 41. https://doi.org/10.36275/stsp.v16i1.53

[11] Septiani, N. A., \& Haitami, D. (2020). Perancangan Sistem Pengarsipan Surat Masuk dan Surat Keluar pada Desa Kampung Besar Menggunakan Metode Alphabetical Filing dan Chronology System. Jurnal Ilmiah Universitas Batanghari Jambi, 20(2), 514. https://doi.org/10.33087/jiubj.v20i2.936

[12] Rahayu, T., Syafril, S., Wekke, I. S., \& Erlinda, R. (2019). Teknik Menulis Review Literatur Dalam Sebuah Artikel Ilmiah. September. https://doi.org/10.31227/osf.io/z6m2y

[13] Mas Diayasa, I. G. S., Sri Rg, N. L. W., Winardi, S., Setiawan, A., Sri Wiwoho, M., Anindito, B., \& Andjarwati, T. (2020). Progressive Parking Smart System in Surabaya's Open Area Based on IoT. Journal 
of Physics: Conference Series, 1569(2). https://doi.org/10.1088/1742$6596 / 1569 / 2 / 022043$

[14] I Gede Susrama, Ariyono Setiawan, Moch. Kholis, (2020). Rancang Bangun Aplikasi "W-Mass (Weight Monitor Assistant)" Berbasis Android Studio Dengan Bahasa Native Java, Jurnal Penelitian Poltekbang, Vol 4 (2), Hal. 1-19.

[15] Gat. (2015). Perancangan Basis Data Perputakaan Sekolah dengan Menerapkan Model Data Relasional. Citec Journal, 2, No. 4(4 agustusoktober 2015), 304-315.

[16] Wiranata, A. (2014). Analisis dan Perancangan Basis Data Terdistribusi Pada PT. Melati Argo Prima.

[17] Robby, Kwanentent, O., \& Wardana, F. M. (2009). Analisis dan Perancangan Basis Data untuk Mendukung Aplikasi ERP Education pada Bina Nusantara University ( Studi Kasus : Academic Management and Content Preparation ). Bina Nusantara University.

[18] Yudo, S. (2018). Perancangan Sistem Basis Data Online Monitoring Kualitas Air Di Sungai Ciliwung. Jurnal Air Indonesia, 9(1) https://doi.org/10.29122/jai.v9i1.2475

[19] Abednego, Dewi, L. P., \& Wibowo, A. (2017). Perancangan dan Pembuatan Sistem Informasi Perpustakaan Berbasis Web pada SMP YBPK 1 Surabaya. Jurnal Infra, Vol 5 No 1, 199-204.

[20] Setiawan, R., Santosa, A., \& Sistem, P. (n.d.). K3Lh-Dp Pt Dirgantara Indonesia.

[21] Bagir, H., \& Putro, B. E. (2018). Analisis Perancangan Sistem Informasi Pergudangan di CV. Karya Nugraha. Jurnal Media Teknik Dan Sistem Industri, 2(1), 30. https://doi.org/10.35194/jmtsi.v2i1.274 